\title{
Streptomyces bangladeshensis sp. nov., isolated from soil, which produces bis-(2-ethylhexyl)phthalate
}

Correspondence

María Elena Flores

mefc@servidor.unam.mx

\author{
M. Abdul Alim Al-Bari, ${ }^{1}$ M. Shah Alam Bhuiyan, ${ }^{1,2}$ María Elena Flores, ${ }^{3}$ \\ Pavel Petrosyan, ${ }^{3}$ Martín García-Varela ${ }^{4}$ and M. Anwar UI Islam ${ }^{1}$ \\ 'Department of Pharmacy, University of Rajshahi, Rajshahi-6205, Bangladesh \\ ${ }^{2}$ Laboratory of Molecular Biotechnology, Department of Biotechnology, The University of Tokyo, \\ Yayoi 113-8657, Japan \\ ${ }^{3}$ Department of Molecular Biology and Biotechnology, Institute for Biomedical Research, \\ UNAM, A.P. 70228, Mexico, D.F., 04510, Mexico \\ ${ }^{4}$ Department of Zoology, Institute of Biology, UNAM, México, D.F., 04510, Mexico
}

\begin{abstract}
The taxonomic position of an actinomycete strain isolated from soil from Natore, Bangladesh, was examined by using a polyphasic approach. The strain, designated AAB- $4^{\top}$, was assigned to the genus Streptomyces on the basis of chemical and morphological criteria. It formed Rectiflexibiles aerial hyphae that carried long chains of rounded spores. The 16S rRNA gene of strain $\mathrm{AAB}-4^{\top}$ was sequenced directly and then compared with those of previously studied streptomycetes following the generation of two phylogenetic trees by using maximum-likelihood and neighbour-joining algorithms. This confirmed the assignment of the novel strain to the genus Streptomyces. This strain showed a high level of $16 \mathrm{~S}$ rRNA gene sequence similarity to Streptomyces thermoviolaceus, Streptomyces thermodiastaticus and Streptomyces longisporus, among others, but could be distinguished from them by phenotypic and physiological traits. This micro-organism produces bis-(2-ethylhexyl)phthalate, an antibacterial and antifungal agent. It is proposed that strain AAB- $4^{\top}$ be classified as a novel species within the genus Streptomyces, as Streptomyces bangladeshensis sp. nov. (type strain, AAB- $4^{\top}=L M G 22738^{\top}=$ NRRL B-24326 $\left.{ }^{\top}\right)$.
\end{abstract}

\section{Introduction}

The genus Streptomyces was proposed by Waksman \& Henrici (1943) and classified in the family Streptomycetaceae on the basis of morphology and cell-wall chemotype. Streptomycetes are Gram-positive, aerobic micro-organisms with DNA G + C contents of 69-78 mol\% (Korn-Wendish \& Kutzner, 1992); they produce extensive branching substrate and aerial mycelia that develop into chains of spores by the formation of cross-walls in the multinucleate aerial filaments (Anderson \& Wellington, 2001). The streptomycetes are widely used in industry because of their ability to produce numerous chemical compounds, including enzymes, antitumour agents and (in the main) antibiotics (Bérdy, 1995).

Published online ahead of print on 6 May 2005 as DOI 10.1099/ ijs.0.63516-0.

The GenBank/EMBL/DDBJ accession number for the 16S rRNA gene sequence of Streptomyces bangladeshensis strain AAB- $4^{\top}$ (=LMG $22738^{\top}=$ NRRL B-24326 ${ }^{\top}$ ) is AY750056.

A neighbour-joining dendrogram is available as a supplementary figure in IJSEM Online.
During routine screening for antibiotic-producing organisms from soil samples from different regions of Bangladesh, an actinomycete was isolated that produced the antibiotic bis-(2-ethylhexyl)phthalate. This strain, designated AAB- ${ }^{\mathrm{T}}$, demonstrated a colonial morphology consistent with its assignment to the genus Streptomyces. The aim of the present investigation was to determine the taxonomic position of this organism, and the results suggest that it should be recognized as a novel species of the genus Streptomyces, for which the name Streptomyces bangladeshensis sp. nov. is proposed.

Strain $\mathrm{AAB}-4^{\mathrm{T}}$ was isolated on yeast extract-glucose agar (Shirling \& Gottlieb, 1966), using serial dilutions, and was selected by means of its antibacterial activity. The strain was maintained on Czapek-Dox (Shirling \& Gottlieb, 1966) alkaline ( $\mathrm{pH} \mathrm{8.0)}$ slants at $4{ }^{\circ} \mathrm{C}$. Strain $\mathrm{AAB}-4^{\mathrm{T}}$ was deposited in the Northern Regional Research Center Culture Collection (Peoria, IL, USA) as strain NRRL B-24326 ${ }^{\mathrm{T}}$ and in the BCCM/LMG Bacteria Collection (Ghent, Belgium) as strain LMG $22738^{\mathrm{T}}$.

Growth and sporulation of strain AAB- $4^{\mathrm{T}}$ were observed on standard media (Table 1); aerial spore-mass colour, 
Table 1. Growth and characteristics of strain $A A B-4^{\top}$ on different media

\begin{tabular}{|lcllll|}
\hline Agar medium & Growth $\dagger$ & Spore mass & \multicolumn{2}{c|}{ Colony colour } & Soluble \\
\cline { 3 - 5 } & & & Aerial mycelia & Substrate mycelia & pigments \\
\hline YEME (ISP2) & +++ & Abundant, yellow & Yellow-green & Beige & Olive green \\
Oatmeal (ISP3) & +++ & Abundant, white & White & Yellowish white & None \\
Glycerol/asparagine & +++ & Abundant, white & Pale white & Light yellow & None \\
Czapek-Dox & +++ & Abundant, white & Grey & White & Yellow \\
Nutrient & + & Poor, white & Yellow & Yellow & None \\
\hline
\end{tabular}

${ }^{\star}$ Media were as described by Shirling \& Gottlieb (1966).

$\dagger+++$, Good growth; + , poor growth.

pigmentation of substrate mycelium and the production of diffusible pigments were recorded following incubation of the strain at $37^{\circ} \mathrm{C}$ for $4-7$ days. Peptone/yeast extract/iron agar and tyrosine agar (Shirling \& Gottlieb, 1966) were used to score the production of melanin pigments.

Strain $\mathrm{AAB}-4^{\mathrm{T}}$ was examined for various phenotypic properties, the results of which are listed in Table 2. Basal mineral salts agar (Hopwood, 1967) with $1 \%(\mathrm{w} / \mathrm{v})$ sole carbon sources was used to assess for carbon utilization.
Antibiotic resistance was determined at $37^{\circ} \mathrm{C}$ on YEME medium (Shirling \& Gottlieb, 1966), using the disc method (Al-Tai et al., 1999). The ability of strain AAB- $4^{\mathrm{T}}$ to inhibit the growth of different bacteria was detected by using the plug technique (Beur et al., 1966; Barry, 1980). Strain AAB$4^{\mathrm{T}}$ spores were inoculated onto Czapek-Dox agar plates and agar discs $(8 \mathrm{~mm})$ of a 7 -day-old culture grown at $37^{\circ} \mathrm{C}$ were transferred to nutrient agar plates (Shirling \& Gottlieb, 1966) that had previously been seeded with different test organisms (as listed in Table 3). The plates were kept

Table 2. Comparison of phenotypic properties of strain $A A B-4^{\top}$, S. thermoviolaceus NRRL $\mathrm{B}-12374^{\top}$, S. thermodiastaticus NRRL B-5316 ${ }^{\top}$ and S. longisporus NRRL B-5336 ${ }^{\top}$

\begin{tabular}{|c|c|c|c|c|}
\hline Property & $\mathrm{AAB}-4^{\mathrm{T}}$ & S. thermoviolaceus & S. thermodiastaticus & S. longisporus \\
\hline Spore colour & Yellow & Grey & Grey & White \\
\hline $\begin{array}{l}\text { Pigmentation of substrate } \\
\text { mycelium }\end{array}$ & White & Yellow/purple & Yellowish brown & White \\
\hline Spore chain & Rectiflexibiles & Spiral $^{*}$ & Spiral $^{*}$ & Rectiflexibiles \\
\hline Spore surface & Smooth & Tuberculate & Tuberculate $e^{\star}$ & Smooth \\
\hline \multicolumn{5}{|l|}{$\begin{array}{l}\text { Growth on sole carbon } \\
\text { sources: } \dagger\end{array}$} \\
\hline L-Arabinose & ++ & + & - & - \\
\hline Fructose & ++ & ++ & + & - \\
\hline Glucose & ++ & ++ & + & + \\
\hline D-Xylose & $+1-$ & ++ & ++ & ++ \\
\hline Mannitol & ++ & ++ & $+1-$ & ++ \\
\hline Sucrose & ++ & ++ & + & - \\
\hline Rhamnose & ++ & - & $+1-$ & ++ \\
\hline Maltose & ++ & ++ & + & ++ \\
\hline$m$-Inositol & ++ & $+1-$ & $+1-$ & ++ \\
\hline Glycerol & ++ & ++ & ++ & + \\
\hline Raffinose & ++ & ++ & + & + \\
\hline Galactose & + & + & ++ & ++ \\
\hline Melezitose & - & - & - & + \\
\hline Mannose & ++ & ++ & ++ & ++ \\
\hline Lactose & - & ++ & + & + \\
\hline Trehalose & ++ & - & - & ++ \\
\hline
\end{tabular}

${ }^{\star}$ Kim et al. (1999).

$\dagger-$, No growth; + , poor growth; ++ , moderate growth. 
Table 3. Antimicrobial activities of strain $A A B-4^{\top}$

\begin{tabular}{|llc|}
\hline Organism & Strain no. & Response $^{*}$ \\
\hline Bacillus subtilis & QL-38 & ++ \\
Bacillus megaterium & QL-40 & + \\
Staphylococcus aureus & ATCC-259233 & ++ \\
Salmonella typhi & & ++ \\
Shigella dysenteriae & AL-35587 & ++ \\
Shigella flexneri & AL-30372 & ++ \\
Escherichia coli & FPFC-1407 & ++ \\
Pseudomonas aeruginosa & CRL & + \\
Candida albicans & ATCC-10231 & ++ \\
Aspergillus niger & & ++ \\
Aspergillus fumigatus & & + \\
Penicillium digitatum & & + \\
Epidermophyton flocosum & & + \\
\hline
\end{tabular}

${ }^{\star}++$, Strongly positive; + , positive.

overnight at $4{ }^{\circ} \mathrm{C}$ and then incubated at $37^{\circ} \mathrm{C}$ for $24 \mathrm{~h}$. Tolerance of the novel strain to $0 \cdot 2,2,4$ and $7 \% \mathrm{NaCl}$ was determined on ISP9 medium (Shirling \& Gottlieb, 1966).

Isolation of chromosomal DNA from strain $\mathrm{AAB}-4^{\mathrm{T}}$ was carried out essentially as described by Hunter (1988). The $16 \mathrm{~S}$ rRNA gene was amplified from purified DNA of the strain as described previously (Petrosyan et al., 2003) using TripleMaster DNA polymerase (Eppendorf). The amplified fragment was purified from the gel by using a QIAquick Gel extraction kit (Qiagen) and then sequenced directly with an ABI Prism BigDye Terminator v2.0 Cycle Sequencing kit (Applied Biosystems). The sequences were obtained with a model 310 Genetic Analyser automated sequencer (Applied Biosystems).

For the identification of bis-(2-ethylhexyl)phthalate, mycelium from 7-day-old culture grown in Czapek-Dox broth $(\mathrm{pH} 8 \cdot 0)$ (Shirling \& Gottlieb, 1966) was separated by filtration and the culture filtrate was extracted twice with ethyl acetate. The organic fraction was evaporated under reduced pressure and the antibiotic was separated and purified by using chromatographic techniques. The pure compound was identified by using one-dimensional $\left({ }^{1} \mathrm{H}\right.$ and $\left.{ }^{13} \mathrm{C}\right)$ and two-dimensional NMR data.

The colonial morphology of strain $\mathrm{AAB}-4^{\mathrm{T}}$ was consistent with its assignment to the genus Streptomyces (Williams et al., 1989). The strain formed a highly branched substrate mycelium and aerial hyphae that differentiated into long Rectiflexibiles spore-chains. On standard media, the colour of the substrate mycelium was beige and that of the aerial spore mass was yellow (Table 1). Strain $\mathrm{AAB}-4^{\mathrm{T}}$ contained LL-diaminopimelic acid, as determined according to the methodology of Staneck \& Roberts (1974).

To confirm that strain AAB- $4^{\mathrm{T}}$ was a streptomycete, we sequenced the almost-complete $16 \mathrm{~S}$ rRNA gene from this micro-organism and compared it with the 16S rRNA gene sequences of previously described streptomycetes. Strain $\mathrm{AAB}-4^{\mathrm{T}}$ has a high percentage of nucleotide sequence similarity to Streptomyces thermoviolaceus NRRL B-12374 ${ }^{\mathrm{T}}$ (98\%), Streptomyces thermodiastaticus NRRL B-5316 ${ }^{\mathrm{T}}$ $(98 \%)$ and Streptomyces longisporus NRRL B-5336 ${ }^{\mathrm{T}}$ (97\%). These values correspond to 20-30 nt differences out of 1421 positions. Nucleotide similarity values within this range have been reported for several Streptomyces species with validly published names and which can be separated from each other on the basis of DNA relatedness data and phenotypic properties (Kim et al., 1999, 2000).

The 16S rRNA gene sequence of strain $\mathrm{AAB}-4^{\mathrm{T}}$ generated in this work (1421 nt; GenBank accession no. AY750056) was aligned with the $16 \mathrm{~S}$ rRNA gene sequences of other streptomycetes obtained from the EMBL/GenBank dataset. The alignment of the sequences was carried out using CLUSTAL $\mathrm{W}$ software (Thompson et al., 1994) and was adjusted manually. The alignment contained $1428 \mathrm{nt}$ from 21 species. To determine which model of sequence evolution best fitted our dataset, a nested likelihood-ratio test was performed using the MODELTEST program, version 3.04 (Posada \& Crandall, 1998). Phylogenetic relationships were inferred using the maximum-likelihood method (Felsenstein, 1981). Fifty random-taxon-addition heuristic searches with the tree bisection-reconnection branch-swapping option were conducted using PAUP ${ }^{*} 4.0 \mathrm{~b} 10$ software (Swofford, 2002). Genetic distances among species were estimated by using the Kimura method (Kimura, 1980). The relationships among taxa were also established by neighbour joining with the MEGA program (Kumar et al., 2001). The robustness of the neighbour-joining and maximum-likelihood trees was evaluated using bootstrapping with 1000 and 10000 replicates, respectively (Felsenstein, 1981).

Nucleotide frequencies for the 16S rRNA gene sequence dataset were $0 \cdot 225(\mathrm{~A}), 0 \cdot 255(\mathrm{C}), 0 \cdot 336(\mathrm{G})$ and $0 \cdot 182(\mathrm{~T})$. The heterogeneity of nucleotide frequencies across taxa was tested using the 'basefreq' option implemented in PAUP* $\left(\chi^{2}=1 \cdot 230, P=1 \cdot 0\right)$. The result indicates that rRNA gene nucleotide frequencies were not significantly heterogeneous across taxa, which is advantageous because the maximumlikelihood inference method performs optimally when nucleotide frequencies are homogeneous (Omilian \& Taylor, 2001). The likelihood-ratio test indicated that the best model to fit the 16S rRNA gene dataset was TamuraNei $(\operatorname{TrN})$ (Tamura \& Nei, 1993), with an equal rate of substitution and a proportion of invariable sites of 0.9035 . A maximum-likelihood analysis using this model yielded a single tree with a $-\ln$ score of $2646 \cdot 11$. The maximumlikelihood tree showed that strain AAB- $4^{\mathrm{T}}$ is a sister species of S. longisporus with a bootstrap value of $52 \%$ (Fig. 1). The tree resulting from the neighbour-joining analysis yielded the same relationship between S. bangladeshensis and Streptomyces longisporus, with a low bootstrap value $(34 \%)$. The neighbour-joining dendrogram showed that the clade composed by both species was a sister clade to the species $S$. 


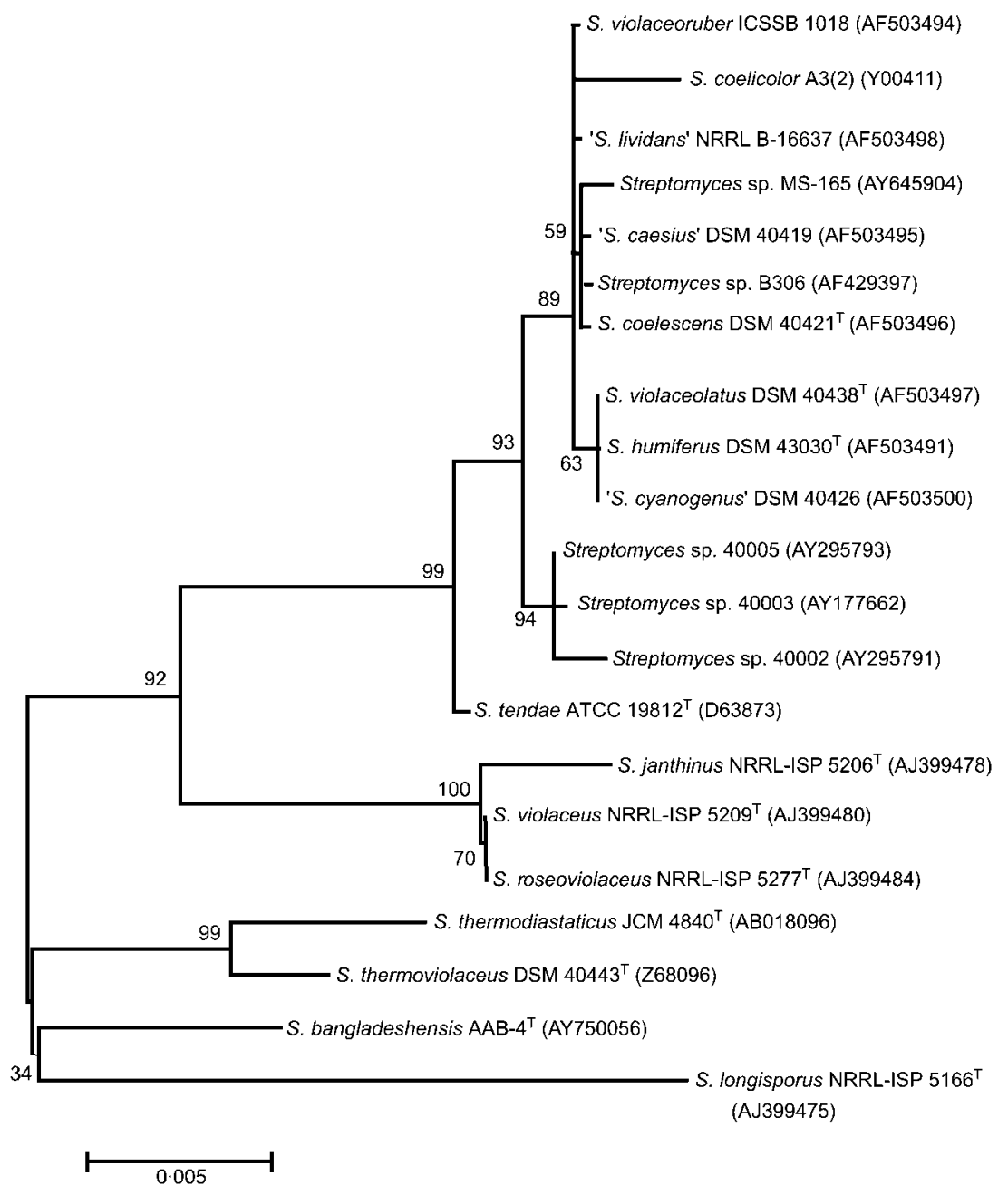

Fig. 1. Maximum-likelihood tree based on 16S rRNA gene sequences. The tree was inferred from a dataset of $1428 \mathrm{nt}$ from 21 strains of Streptomyces. The - In likelihood is 2646-11. Branch lengths are proportional to the inferred number of nucleotide substitutions. Numbers below internal nodes show maximumlikelihood clade frequencies. GenBank accession numbers are in parentheses. thermoviolaceus and $S$. thermodiastaticus (see Supplementary Figure, available in IJSEM Online).

The novel strain had a number of phenotypic characteristics that distinguish it from related micro-organisms. As can be seen in Table 2, strain $\mathrm{AAB}-4^{\mathrm{T}}$ differs from S. longisporus in spore colour, soluble pigment formation, growth on Larabinose, fructose, xylose and sucrose, and, less strikingly, on glucose, glycerol, raffinose, galactose, melezitose and lactose as sole carbon sources. The differences between $\mathrm{AAB}-4^{\mathrm{T}}$ and $S$. thermodiastaticus and $S$. thermoviolaceus include such morphological traits as spore-chain shape and colour, pigmentation of substrate mycelium, and growth on rhamnose, $m$-inositol and lactose (for $S$. thermoviolaceus) and L-arabinose, D-xylose, mannitol, rhamnose, $m$-inositol and trehalose (for $S$. thermodiastaticus). The physiological properties of strain $\mathrm{AAB}-4^{\mathrm{T}}$ are presented in the species description below.

When grown in Czapek-Dox broth ( $\mathrm{pH} 8 \cdot 0)$ medium, strain $\mathrm{AAB}-4^{\mathrm{T}}$ produced the antimicrobial agent bis-(2ethylhexyl)phthalate, previously isolated from Streptomyces melanosporofaciens (Kim et al., 1991). The compound was identified by ${ }^{1} \mathrm{H}$ and ${ }^{13} \mathrm{C}$ NMR and showed significant activity against Gram-positive and -negative bacteria and some fungi (Table 3). However, these two micro-organisms are different with respect to their phenotypic characteristics (Kim et al., 1990) and their 16S rRNA gene sequences (GenBank accesssion no. AJ391837).

The genotypic and phenotypic data suggest that strain AAB$4^{\mathrm{T}}$ should be recognized as a novel species of the genus Streptomyces, for which we propose the name Streptomyces bangladeshensis sp. nov.

\section{Description of Streptomyces bangladeshensis sp. nov.}

Streptomyces bangladeshensis (ban.gla.desh.en'sis. N.L. masc. adj. bangladeshensis belonging to Bangladesh, the source of the soil from which the organism was isolated).

Aerobic, Gram-positive, moderately thermophilic actinomycete. Forms highly branched substrate mycelium and aerial hyphae that differentiate into long Rectiflexibiles chains of eight to ten spores. Aerial spore-mass colour is 
yellow-green. Substrate mycelium is beige on standard media. Yellowish diffusible pigments are formed on Czapek-Dox agar. Melanin pigments are not produced on peptone/iron or tyrosine agars. Positive for $\mathrm{H}_{2} \mathrm{~S}$ production. Utilizes glucose, sucrose, $m$-inositol, mannitol, mannose, maltose, fructose, L-arabinose, rhamnose, glycerol, raffinose and trehalose as sole carbon sources. Growth occurs at $20-50{ }^{\circ} \mathrm{C}$, at $\mathrm{pH} 6 \cdot 0-11 \cdot 0$ and in the presence of $2 \%$ $(\mathrm{w} / \mathrm{v}) \mathrm{NaCl}$, neomycin sulfate $\left(50 \mu \mathrm{g} \mathrm{ml}^{-1}\right)$ and penicillin $\left(10 \mathrm{IU} \mathrm{ml}^{-1}\right)$. Produces bis-(2-ethylhexyl)phthalate, an antimicrobial agent.

The type strain is $\mathrm{AAB}-4^{\mathrm{T}}$ (=LMG $22738^{\mathrm{T}}=\mathrm{NRRL}$ B$24326^{\mathrm{T}}$ ). Isolated from soil from Natore, Bangladesh.

\section{Acknowledgements}

We are very grateful to Dr D. Labeda for providing the strains of S. thermoviolaceus, S. thermodiastaticus and S. longisporus, and to Patricia De la Torre for DNA sequencing.

\section{References}

Al-Tai, A., Kim, B., Kim, S. B., Manfio, G. P. \& Goodfellow, M. (1999). Streptomyces malaysiensis sp. nov., a new streptomycete species with rugose, ornamented spores. Int J Syst Bacteriol 49, 1395-1402.

Anderson, A. S. \& Wellington, E. M. H. (2001). The taxonomy of Streptomyces and related genera. Int J Syst Evol Microbiol 51, 797-814.

Barry, A. L. (1980). Procedure for testing antimicrobial agents in agar media: theoretical consideration. In Antibiotics in Laboratory Medicine, pp. 1-23. Edited by V. Lorian. Baltimore: Williams \& Wilkins.

Bérdy, J. (1995). Are actinomycetes exhausted as a source of secondary metabolites? Biotechnologia 7-8, 13-34.

Beur, A. W., Kirby, W. M. M., Sherris, J. C. \& Turck, M. (1966). Antibiotic susceptibility testing by a standardized single disk method. Am J Clin Pathol 45, 493-496.

Felsenstein, J. (1981). Evolutionary trees from DNA sequences: a maximum likelihood approach. J Mol Evol 17, 368-376.

Hopwood, D. A. (1967). Genetic analysis and genome structure in Streptomyces coelicolor. Bacteriol Rev 31, 373-403.

Hunter, I. S. (1988). Gene cloning in Streptomyces. In DNA Cloning: a Practical Approach, vol. 2, pp. 19-44. Edited by D. M. Glover. Washington, DC: IRL Press.

Kim, S.-K., Kim, S.-S. \& Kim, C.-H. (1990). New antibiotics produced by Streptomyces melanosporofaciens. I. Taxonomy of the producing microorganism. Kor J Appl Microbiol Biotechnol 18, 624-632.

Kim, S.-K., Kim, S.-S., Kim, K.-S., Chung, Y.-R. \& Kim, C.-H. (1991). New antibiotics produced by Streptomyces melanosporofaciens. II.
Antimicrobial activities and isolation, purification, and structure determination of the active compound. Kor J Appl Microbiol Biotechnol 19, 235-241.

Kim, B., Sahin, N., Minnikin, D. E., Zakrzewska-Czerwinska, J., Mordarski, M. \& Goodfellow, M. (1999). Classification of thermophilic streptomycetes, including the description of Streptomyces thermoalcalitolerans sp. nov. Int J Syst Bacteriol 49, 7-17.

Kim, B., Al-Tai, A. M., Kim, S. B., Somasundaram, P. \& Goodfellow, M. (2000). Streptomyces thermocoprophilus sp. nov., a cellulase-free endo-xylanase-producing streptomycete. Int J Syst Evol Microbiol 50, 505-509.

Kimura, M. (1980). A simple method for estimating evolutionary rates of base substitutions through comparative studies of nucleotide sequences. J Mol Evol 16, 111-120.

Korn-Wendish, F. \& Kutzner, H. J. (1992). The family Streptomycetaceae. In The Prokaryotes, pp. 921-995. Edited by A. Balows, H. G. Trüper, M. Dworkin, W. Harder \& K. H. Schleifer. New York: Springer.

Kumar, S., Tamura, K., Jakobsen, I. B. \& Nei, M. (2001). MEGA2: molecular evolutionary genetic analysis software. Bioinformatics 17, 1244-1245.

Omilian, A. R. \& Taylor, D. J. (2001). Rate acceleration and longbranch attraction in a conserved gene of cryptic daphniid (Crustacea) species. Mol Biol Evol 18, 2201-2212.

Petrosyan, P., García-Varela, M., Luz-Madrigal, A., Huitrón, C. \& Flores, M. E. (2003). Streptomyces mexicanus sp. nov., a xylanolytic micro-organism isolated from soil. Int J Syst Evol Microbiol 53, 269-273.

Posada, D. \& Crandall, K. A. (1998). MODELTEST: testing the model of DNA substitution. Bioinformatics 9, 817-818.

Shirling, E. B. \& Gottlieb, D. (1966). Methods for characterization of Streptomyces species. Int J Syst Bacteriol 16, 313-340.

Staneck, J. L. \& Roberts, G. D. (1974). Simplified approach to identification of aerobic actinomycetes by thin-layer chromatography. Appl Microbiol 28, 226-231.

Swofford, D. L. (2002). PAUP*: Phylogenetic Analysis Using Parsimony (and other methods), version 4.0b10. Sunderland, MA: Sinauer Associates.

Tamura, K. \& Nei, M. (1993). Estimation of the number of nucleotide substitutions in the control region of mitochondrial DNA in humans and chimpanzees. Mol Biol Evol 10, 512-526.

Thompson, J. D., Higgins, D. G. \& Gibson, T. J. (1994). CLUSTAL W: improving the sensitivity of progressive multiple sequence alignment through sequence weighting, position-specific gap penalties and weight matrix choice. Nucleic Acids Res 22, 4673-4680.

Waksman, S. A. \& Henrici, A. T. (1943). The nomenclature and classification of the actinomycetes. J Bacteriol 46, 337-341.

Williams, S. T., Goodfellow, M. \& Alderson, G. (1989). Genus Streptomyces Waskman and Henrici 1943, 339 ${ }^{\mathrm{AL}}$. In Bergey's Manual of Systematic Bacteriology, vol. 4, pp. 2452-2492. Edited by S. T. Williams, M. E. Sharpe \& J. G. Holt. Baltimore: Williams \& Wilkins. 